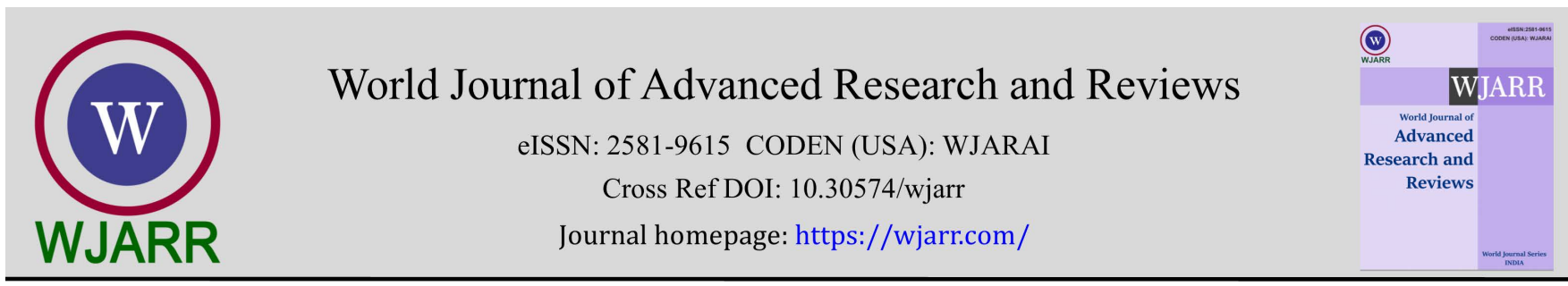

(REVIEW ARTICLE)

Check for updates

\title{
Monitoring noise level in cities: A step towards urban environmental quality management in Nigeria
}

\author{
MeeluBari Barinua Tsaro Kpang 1,* and Osademe Chukwudi Dollah ${ }^{2}$ \\ ${ }^{1}$ Department of Geography and Environmental Management, Faculty of Social Sciences, University of Port Harcourt, Port \\ Harcourt, Nigeria. \\ 2 Institute of Geosciences and Environmental Management, Faculty of Social Sciences, Rivers State University, Port \\ Harcourt, Nigeria.
}

World Journal of Advanced Research and Reviews, 2021, 10(03), 348-357

Publication history: Received on 17 April 2021; revised on 20 June 2021; accepted on 23 June 2021

Article DOI: https://doi.org/10.30574/wjarr.2021.10.3.0194

\begin{abstract}
Noise as an undesirable sound within non-occupational settings is one of the several identified environmental problems across the world. It is an increasing common feature of urban areas attributable to road, rail, and air traffic sources as well as construction and industrial activities, commercial enterprise, and such familiar domestic sources as pets and radios/stereos from residential neighborhood. Noise is a major pollution which constitutes nuisances and health related consequences of significant negative impacts on the physical, social, physiological and psychological wellbeing of man or animals. It is notably evident that increased activities from industrialization and technological transfers/drifts are the bedrock of urban noise in majority of our rapid growing cities at present. At the instance of sufficient evidence that noise aggravates chronic illnesses like hypertension and other cardiopulmonary diseases, the World Health Organization (WHO) and the Federal Environment Protection Agency (FEPA) (Nigeria) has strategically set standards and limits of allowable noise levels which unfortunately is not implemented and enforced in most cities, thereby leading to urban quality deterioration. Noise pollution occurs when it is observed that standards are exceeded, therefore concerted efforts in monitoring and regulating our environmental noise is recommended to avert the scourge of further debasement of environmental quality in our cities.
\end{abstract}

Keywords: Monitoring; Noise; Nigeria; Urban environmental quality; Cities, Management.

\section{Introduction}

Our society has undoubtedly evolved from the primitive settlements characterized by crude technology meant only for feeding, sheltering, clothing, and survival, that existed thousands of years ago into contemporary, highly complex, and interwoven existing one, such as towns, cities, and mega cities, which are basically driven by sophisticated technologies geared towards provision of, not only basic human needs, but also services that meet diversified socio-economic and political needs of modern man [56]. The process of urbanization with its incremental growth and complexity in world urban settlements brings about social, cultural, economic, political, and ecological changes in the human settlement landscape. Therefore, urbanization involves a culmination of factors such as population explosion, spatial expansion as well as political and service complexity which result in processes that cause marked and persistent modifications in land-use activities and interactions $[30,60]$. These changes have some negative consequences particularly noise pollution which has become an issue in global human development and sustainability. The world urban population is greatly exposed to potentially harmful noise levels due to increasing trend in commercialization, mobility and urbanization of human settlements across the world. Noise pollution is ranked the third most dangerous environmental

${ }^{*}$ Corresponding author: MeeluBari Barinua Tsaro Kpang

Department of Geography and Environmental Management, Faculty of Social Sciences, University of Port Harcourt, Port Harcourt, Nigeria.

Copyright (c) 2021 Author(s) retain the copyright of this article. This article is published under the terms of the Creative Commons Attribution Liscense 4.0. 
pollution, after exhaust emissions pollution and water pollution and as an unwanted and uninterrupted sound which can cause annihilation of calmness constitutes a fundamental component of environmental pollution with significant impact on the quality of life in urban areas $[33,41]$. It is a major pollution in contemporary urban settlements of many developed countries of the world but with serious concerns. However, despite been identified as an agent for loss of environmental and life quality in a metropolis, it is increasingly becoming a norm and typical of most developing countries like Nigeria wherewith little or no concern has been raised. According to the World Health Organization [70], speech interference, reduction in productivity, high blood pressure, hearing defects, health disorders, sleep interference, cardiovascular effects, loss of concentration, absenteeism, and fatigue are some of the health implications of high levels of noise. Additionally, noise is also described as slow and subtle killer through its hazardous effects on humans [8, 35]. This paper therefore presents the needs for adequate monitoring of noise levels in the urban environment composed of several audible sources: Traffic (road, rail, and air), industrial facilities, civil construction and social activities (parties, fairs and open air markets, and residential noise) which threatened environmental quality in urban areas.

\section{Sources of noise pollution in urban centres}

Noise is audible unwanted sound that poses threat to a person's health and well-being and usually described in terms of loudness (intensity) and pitch (frequency) and comprises of basically single or mixture of sound waves of different sound levels that are produced by a variety of sources such as industrial and commercial activities, including operations of factories and workshops, transport activities, constructions activities and social activities in urban settlements, including market places, sports events and entertainments [64]. The sources of noise in many cities are usually described to be generated from different sources and some of the prominent sources of noise pollution already documented are loud music from concerts, religious buildings like churches and mosques, the ones from generators, political rallies, road advertisement, and traffic and air transportation sporting events, construction and industrial activities and also residential places near to major roads [29, 52, 5]. However, many of the more significant and preventable sources arise from traffic and industry while motor vehicle traffic stand as the single greatest contributor of noise in most cities. Motor vehicle noise, including noise from automobiles, motorcycles, buses, and trains, is a result of (1) vehicle traction systems including the engine, braking, exhaust (2) the interface of the wheel and the road or rail and (3) displacement of air, which is important at high speeds. Many noise complaints result from proximity of housing to businesses, industries, and institutional uses. Residential-industrial noise conflicts arise from mechanical equipment, loading and unloading of delivery vehicles, heavy truck backup beepers, generators, and refrigeration equipment.

Table 1 Sound levels generated by various sources of noise

\begin{tabular}{|l|c|}
\hline \multicolumn{1}{|c|}{ Sound Level } & dbA \\
\hline Quiet library, soft whispers & 30 \\
\hline Quiet room & 40 \\
\hline Normal conversation & 60 \\
\hline Air conditioner at 20 feet, sewing machine & 60 \\
\hline Vacuum cleaner, hair dryer, noisy restaurant & 70 \\
\hline Moderate traffic & 75 \\
\hline Heavy Traffic & 85 \\
\hline Subway, motorcycle, truck traffic, lawn mower & $90-100$ \\
\hline Garbage truck, pneumatic drill & 100 \\
\hline Chain saw & 110 \\
\hline Rock band concert in front of speakers, thunderclap & 120 \\
\hline Emergency Response Siren, Jet takeoff & 120 \\
\hline Jackhammer & 130 \\
\hline Gunshot blast, Jet engine & 140 \\
\hline Rocket launching pad & 180 \\
\hline
\end{tabular}




\subsection{Land use-based analysis of noise pollution levels}

It is generally established by many that the trend of noise pollution is increasing particularly in terms of it magnitude and severity with more extensive reach, arising from population growth, technological development and urbanization [22]. The process of incremental growth and complexity in world urban settlements specifically referred to as urbanization has been described as one of the major problems of the world today. In contemporary times the human society has evolve from the primitive settlements that existed thousands of years ago, basically characterized by simple technology to highly complex urban settlements largely driven by sophisticated technologies developed to provide, not only basic human needs, but also services that run the day-to-day, diversified socio-economic and political activities of modern man $[72,56]$. The human environment has become increasingly shaped by urbanization and the built environment, which comprises the physical infrastructure arising from urban development as well as managed green space such as urban forests, parks, and sport fields is currently gaining deserved attention of public and environmental health researchers, following the fact that inherent quality, characteristics, and spatial orientation (i.e., urban sprawl) have been linked to a rise in the occurrence of diverse health related problems, as well as a growing culture of sedentary living, contributing to the emergence of numerous chronic diseases [20,31,12]. Urbanization in its true sense has been described as a culmination of factors resulting in processes that cause marked and persistent modifications in land-use activities and interactions; thus leading to population explosion, spatial expansion as well as political and service complexity $[30,60]$. The urbanization process brings about serious modification in the social, cultural, economic, political, and ecological constituents of the human settlement landscape. And these changes obviously have some negative consequences such as rise in energy consumption and global climate change $[4,13,39]$, degrading urban ecology $(69,32]$, urban land degradation and increased disaster rate $[34,18,15]$, profound cultural change and infiltration $[24,23]$, as well as extreme generation of hazardous waste $(61,55,58,71]$ among others which have become issues of global concern in human development and sustainability.

\subsection{Noise pollution as a degrading factor of urban environmental quality}

Although, noise pollution concentrates around cities, it is not exclusive to urban areas. As reported by (PRB, 2015), less than $14 \%$ of the world's population lived in urban environments at the beginning of the 20th century whereas there is a dramatic shift from that position today as it is obvious that more than half live in a city. The United Nations, Department of Economic and Social Affairs, Population Division in 2014 stated that in industrialized nations, the number of urban dwellers is much higher (80\%), with Europe's urban population predicted to exceed 580 million across 48 nations by 2050. Urban living creates opportunity for people to be closer to their jobs and also allows industry and creativity to flourish, but it may be associated with a more stressful social environment and greater social inequalities. It is asserted that growing up in a city is linked to higher stress levels, thus clearly suggesting that People living in cities are at increased risk of chronic health disorders wherewith it has been estimated that urban dwellers at the risk of anxiety disorders is $21 \%$ higher and those at the risk of mood disorders is $39 \%$ higher. One of the main types of pollution in urban settlement areas is noise arising from varying sources attributable to anthropogenic activities. Thus, in 1972, the World Health Organization (WHO) declared noise as a pollutant [47]. Noise pollution has been identified and consequently described as one of the core agents of loss of environmental and life quality due to the negative effects it has on human health. Though, its perception is premised on the interrelationship between person, place, and activity in space and time. In other words, the sensitivity of noise is determined by the physical and emotional frame of the person or people exposed to it affects the internal states, including physiological, psychological, and attitudinal makeup of individuals, which increases their degree of reactivity to noise. This implies that noise reflects certain interrelationships between the attitudes of a person, the desire for its control through standards, and the characteristics of the physical stimulus of each type of sound. This therefore indicates that the basic line of distinction between sound and noise is that, while sound is a sensory perception, noise represents undesired and displeasing sound [54]. On a general note, noise is therefore declared as sound made out of place [21]. Apart from creating a nuisance to the urban environment which is considered as the major consequences associated with noise pollution, it also has other implications such as psychological, physiological, and physical effects on exposed populations [40, 25, 45]. In specific terms, deafness, tinnitus, cardiac problems, such as hypertension ischemic heart disease and vasoconstriction, sleep interferences, headaches, fatigue, stomach ulcers, vertigo, and aggression have been attributed to noise pollution [37; 70]. The effects of exposure to noise on the human organism are dependent on the specific qualities of the noise, for example frequency, intensity, and exposure time, and also individual susceptibility.

Noise pollution has been described in several studies conducted in most cosmopolitan cities as the third most hazardous form of pollution beside air and water pollution and contributes immensely to environmental degradation and poses serious danger to human and terrestrial lives [70]. It is generated from a variety of sources including road, railway and air traffic, neighborhood activities, construction and public works. Before now, environmental pollution was primarily considered within the purview of chemical and other noxious substances being extruded into the environment with little or no attention to noise as a form of pollution on account of the fact that it leaves no residual accumulation in the 
environment or the human body [36]. However, the erroneous assumption that "noise leaves no visible evidence" has been debunked by result from studies such as $(67,26]$ which revealed the widespread deleterious effect of noise in both its' course and post-occurrence periods. Similarly, [26, 2] also revealed that noise has undesirable impact on the physical, social and psychological wellbeing of man and can lead to either permanent or temporary hearing loss. Other adverse impact of noise pollution includes acoustic trauma, tympanic membrane perforations and acicular chain disarticulations while exposure to noise levels higher than $80 \mathrm{~dB}$ for a prolonged period is reported to be associated with deafening, while sound levels between 130 and $140 \mathrm{~dB}(\mathrm{~A})$ are described as pain $[68,7,10,38]$. Noise pollution has also been proven to exacerbate chronic illnesses like hypertension and other cardiopulmonary diseases. Relationship between noise and cardiovascular disease (CVD) has been established by different recent studies. Other adverse effects of noise well documented in several studies are sleeping disturbance, annoyance and anxiety disorders. Consequently, some studies have summarily referred to noise pollution as a modern plague $[22,10,3,43,67]$.

Environmental noise can be described as an unwanted or undesirable sound within non-occupational settings and this is perceived to be an increasingly common feature of urban areas with road, rail, and air traffic sources attributed as the major contributor of noise in urban and surrounding areas [9]. Similarly, industrial/commercial enterprise, construction projects, and such known domestic sources as pets and radios/stereos are also included as additional sources of noise. A number of non-auditory, biologically related health problems including increased levels of hypertension and high blood pressure [59], lowered cognitive ability [66] and an increased prevalence of cardiovascular disease [6] have been linked to environmental noise. On the other hand, exposure to environmental noise particularly from traffic-related sources is described as the most annoying of all urban pollution types as it basically affects sleep and rest patterns and also interfere with enjoyment of daily activities $[14,11,63]$. The level of noise in many cities can actually cause serious and long-term damage to health, urban noise therefore affects more than quality of life issue as it does not only make hearing, concentrating, and working specifically difficult but also disturbs sleep. Meanwhile, insufficient or poor-quality sleeps results in stress, fatigue, and changes in body's chemical balances. In consonance with the report of the researches stated here, 20-28\% of urban populations in a recent Canadian survey, attributed noise from road traffic to disruptions during sleep, conversation, and communication tasks such as reading and writing [42].Thus, both in Canada and other countries such as Italy, Australia etc few studies involving field measurements to assess levels of environmental noise have been conducted, however, it remain an unknown fact whether recent trends towards the intensification of urban development will impact environmental noise levels and in turn population health. In view of the fact that human beings are continuously exposed to noise in different daily activities, [46] suggested that it is necessary to develop tools for assessing the annoyance occurring during leisure time, at work and also at home. This has led to development of acceptable noise level guidelines by several agencies based on levels of annoyance, interference with communications, disturbance to sleep, and the potential to cause hearing impairments [47]. For example, the US Environmental Protection Agency recommended a maximum indoor noise level of $45 \mathrm{~dB}$ (A) and outdoor noise level of $55 \mathrm{~dB}$ to allow for intelligible communication. On account of the fact that values are usually derived for specific settings and time period's agencies such as the Italian legislation in 1997 provide guidelines according to land use and population density. Generally, recommended urban residential noise levels range from 45 to $55 \mathrm{~dB}$ depending on the time of day and location of measurement. In the same vein, noise levels in urban residential neighborhoods are prescribed by Australian Environmental Protection Authority noise guidelines not to exceed $55 \mathrm{~dB}$ (A) during the day and $47 \mathrm{~dB}(\mathrm{~A})$ at night (i.e., from 22:00 to 06:00). In furtherance, in 2002 another milestone achievement was recorded as the European Union adopted the Directive 2002/49/CE20 concerning the assessment and management of environmental noise, aimed at controlling and reducing sound pollution using a common approach and avoiding or preventing the harmful effects of noise exposure. The EU established the enforcement of developing strategic noise maps that should estimate the exposure to outside ambient noise, based on assessment methods in agreement to the EU levels.

\subsection{Public health consequences of noise pollution}

Noise pollution is one of the several globally recognized environmental pollutions and it is conceptualized as the circulation of noise with a harmful physiological and psychological impact on humans or animals' lives. On the basis of components such as active populations, road traffic, industry, and construction, cities are expectedly noisy places and a leading source of dissatisfaction for city residents as sounds from various sources interferes with different cognitive functions including attention, concentration, memory, reading ability, and sound discrimination. On a more serious note, the long-term consequences of these effects on children 's development are particularly significant. Again, long term exposure to noise from road, rail, and air traffic results in both physiological and psychological stress, which is indirectly linked to heart disease, and high blood pressure. It is also reported that chronic or repeated exposure to sounds at or above 85 decibels can cause hearing loss [50]. Apart from hearing loss or impairment which is the most common manifestation of noise pollution [28], other physiological and psychological adverse effects of noise pollution exist. And abundance of evidence in the literature reveal examples of these effects to include damage on fetal development, 
annoyance and anxiety [53] mental health catastrophe [19], sleep disturbance and insomnia, cardiovascular disorders in pregnant women [57, 62],respiratory ailments, dizziness and tiredness in school children [1,65],high blood pressure and cognitive difficulties in adults [16,48], cardiocerebrovascular diseases, type 2 diabetes incidence[51] and medically unexplained physical symptoms including other auditory and non-auditory effects such as myocardial infarction incidence, peptic ulcers [44] and disruption of communication and retentive capabilities in children. Consequently, noise pollution is noted for serious deleterious effect on the entire planet $[17,49]$ which cannot be over-emphasized. Consequent upon the foregoing, the World Health Organization (WHO) and the Federal Environment Protection Agency (FEPA) (Nigeria) has set standards and limits of allowable noise levels. Noise pollution is considered to have occurred when it is observed that the set standards are exceeded. However, irrespective of the achievement in noise pollution levels in some developed countries, such as the United States of America, Australia, and Japan, existing noise regulations in Nigeria, as in many other developing countries, have not been effective or do not have regulations/legislation on noise pollution for various reasons ranging from lack of government political will; no handy information on the harmful effect of noise on environmental life and the ecosystem as well as inability to define, evaluate and devise control measures for environmental noise particularly that of neighborhood origin. Therefore, the worsening situation of noise pollution in the country continues to impact negatively on the general public health typically because noise pollution has not been upgraded to the level of the other forms of pollution. And also following the fact that recommended strategies on tackling noise pollution arising from the findings of several studies conducted has not been graciously considered and implemented.

\subsection{Management and control of urban noise pollution in Nigeria}

Table 2 Noise sources in cities and control measures

\begin{tabular}{|c|c|c|}
\hline Categories & Sources & Preferred Actions \\
\hline Various Land uses & $\begin{array}{l}\text { Noise is generated from businesses } \\
\text { premises including markets, } \\
\text { restaurants, bars, shops, and auto } \\
\text { services because of delivery vehicles, } \\
\text { ventilation or refrigeration equipment, } \\
\text { the use of powered machines and } \\
\text { tools, and musical equipment. }\end{array}$ & $\begin{array}{l}\text { Implementation of zoning controls } \\
\text { and other land use policies to limit or } \\
\text { avoid the proximity of noisy and } \\
\text { noise-sensitive uses. }\end{array}$ \\
\hline Construction & $\begin{array}{l}\text { Constructions are usually noisy } \\
\text { because of heavy equipment such as } \\
\text { pile drivers and bulldozers, as well as } \\
\text { saws, jackhammers, and trucks, } \\
\text { particularly when it occurs during } \\
\text { evening and morning hours. }\end{array}$ & $\begin{array}{l}\text { Implementation and enforcement of } \\
\text { policies limiting the use of } \\
\text { construction equipment at night as } \\
\text { well as use of quiet equipment when } \\
\text { construction occurs at night or near } \\
\text { sensitive uses, such as hospitals. }\end{array}$ \\
\hline $\begin{array}{l}\text { Traffic } \\
\text { Noise }\end{array}$ & $\begin{array}{l}\text { Traffic noises are mostly generated } \\
\text { from Trucks, buses, and other vehicles } \\
\text { and are major source noise in most } \\
\text { urban areas. }\end{array}$ & $\begin{array}{l}\text { Appropriate control measures by } \\
\text { Federal and State agencies limit noise } \\
\text { levels. } \\
\text { Approval for use of public service and } \\
\text { transit vehicles (e.g. electric and } \\
\text { hybrid buses). } \\
\text { Regulating speed of vehicles, use of } \\
\text { vehicle alarms and back up beepers } \\
\text { can limit general traffic noise. }\end{array}$ \\
\hline $\begin{array}{l}\text { Machinery and } \\
\text { Equipment }\end{array}$ & $\begin{array}{l}\text { Commercial and residential buildings } \\
\text { have fixed mechanized and powered } \\
\text { equipment for either operation of a } \\
\text { business or for ventilation, air } \\
\text { conditioning, refrigeration, transport, } \\
\text { and other needs. }\end{array}$ & $\begin{array}{l}\text { Cities can ensure machinery and } \\
\text { equipment installed in new buildings } \\
\text { are as quiet as possible. } \\
\text { Implementation and enforcement of } \\
\text { noise standards for loud machinery } \\
\text { and equipment. Restriction on the use, } \\
\text { location, or timing of specific } \\
\text { equipment or activities to protect } \\
\text { health and sleep. }\end{array}$ \\
\hline
\end{tabular}




\begin{tabular}{|l|l|l|}
\hline \multirow{5}{*}{ Residential Areas } & $\begin{array}{l}\text { Noise from residential } \\
\text { neighbourhoods are mainly from } \\
\text { sources within the building such as } \\
\text { other occupants or building systems, } \\
\text { or from external sources such as traffic } \\
\text { and nearby business premises. }\end{array}$ & $\begin{array}{l}\text { Adoption of building standards to } \\
\text { require quiet interiors. } \\
\text { Enforcement of noise standards in } \\
\text { residential areas. } \\
\text { Subsidize acoustical retrofits (e.g. } \\
\text { double pane windows, mechanical } \\
\text { ventilation) for existing residential } \\
\text { buildings near traffic noise sources. }\end{array}$ \\
\hline Entertainment & $\begin{array}{l}\text { Mostly generated from amplified } \\
\text { sound systems in bars, restaurants, } \\
\text { and clubs. } \\
\text { Outdoor gatherings and event centres } \\
\text { and entertainment venues often } \\
\text { contribute significantly to disrupt } \\
\text { surrounding neighbourhoods. }\end{array}$ & $\begin{array}{l}\text { Approval of permit and monitoring of } \\
\text { building insulation and limiting hours } \\
\text { of operation. } \\
\text { Regulation of outdoor public events to } \\
\text { limit noise impacts. }\end{array}$ \\
\hline
\end{tabular}

Noise is a disturbance to the human environment that is inevitable and escalating at such a high rate that is becoming a major threat to the quality of human lives. Noise levels in, urban areas, particularly has been increasing rapidly due to different anthropogenic activities from all facets of land uses. There are numerous physiological and psychological deteriorations that accompany this inevitable part of our lives on the human environment. Some of the most major sources of noise are domestic, industrial, produced by construction works, and transport.

\section{Conclusion and Recommendation}

In the past, environmental pollution was principally considered as emanating from chemical and other noxious substances being introduced and accumulated into the environment. Noise as a form of pollution was not given adequate attention as deserved on account of the fact that noise differs from other forms of pollution in that, once abated, noise leaves no residual accumulation in the environment or the human body [36]. This erroneous conception that "noise leaves no visible evidence" has been vehemently discredited as results from outstanding researches revealed that noise in both its' course and post-occurrence periods have pervasive deleterious effect of on the physical, social and psychological wellbeing of man [26, 27]. Noise is a biological stressor that triggers autonomic chemical mechanisms for arousal and alertness. Consequentially, noise may cause or aggravate conditions related to chronic stress or illnesses like hypertension and other cardiopulmonary diseases. Chronic exposure to elevated levels of community noise creates significant health risks which produces measurable physiological reactions, such as increase in heart rate and body movements and can cause disturbances of natural sleep patterns by causing shifts from deep to lighter stages and these health impacts of noise sufficiently depend on the intensity, duration of exposure, and the context of exposure of the noise. The trend of noise pollution which is on the increase in magnitude and severity in most of our fast-growing cities is fundamentally, due to increased activities from population growth, technological advancement, industrialization and urbanization. It is quite unfortunate that many developing countries including Nigeria do not have regulations/legislation on noise pollution irrespective of its deleterious effect on environmental life and the ecosystem. In attempt to address the aftermath of noise pollution, the Environmental Noise Directive aimed at reducing the harmful effects of noise was promulgated. Regrettably, the directive does not set any limits or targets or prescribe specific measures to be taken, rather leaves the decision to member states to map noise levels from identifiable sources and to draw up action plans to deal with the issue of extreme noise pollution. Consequently, noise pollution as a modern plague currently attacking our cities with its far-reaching implications requires concerted efforts by both individuals and government particularly in monitoring and regulating environmental noise to maintain or guarantee environmental quality in our cities. This is imperative in order to avoid further degradation in environmental quality and deterioration in health status of urban dwellers.

\section{Compliance with ethical standards}

\section{Acknowledgments}

Ukeme Obo Abednego is here acknowledged for her field report which forms the core of this work. 


\section{Disclosure of conflict of interest}

No conflict of interest

\section{References}

[1] Adetoun MB, Blangiardo M, Briggs DJ, Hansell AL. Traffic air pollution and other risk factors for respiratory illness in schoolchildren in the Niger-delta region of Nigeria. Environmental Health Perspectives. 2011; 119(10):14781482 .

[2] Ahmed HO, Dennis JH, Badran O, et al. Occupational noise exposure and hearing loss of workers in two plants in eastern Saudi Arabia. Annual Occupational Hygiene 2001; 45(5):371-380.

[3] Agarwal S, Swami BL. Noise annoyance under interrupted traffic flow condition for Jaipur City. International Journal of Applied Science and Engineering. 2009; 7(2):159-168.

[4] Al-Mulalia U, Ozturkb L. The effect of energy consumption, urbanization, trade openness, industrial output, and the political stability on the environmental degradation in the MENA (Middle East and North African) region. Energy. 2015; 84:382-389.

[5] Asuquo U, Onuu M, Asuquo A. Effects of Exposure to Loud Noise on the Hearing of the Residents of Calabar, Nigeria. Can. Acoustic. 2012; 40:50-51.

[6] Babisch W. Traffic noise and cardiovascular disease: epidemiological review and synthesis. Noise Health. 2000;8:9-32.

[7] Berglund B, Lindvall T.Center for Sensory Research. Stockholm University and Karolinska Institute; Stockholm, Swenden. Community noise. 1995.

[8] Birgitta B,Lindvall H. A Draft Document of Community Noise, WHO Environmental Health Criteria 12, World Health Organization, Geneva. 1995.

[9] Brown AL, Lam KC. Urban noise surveys. Applied Acoustics. 1987; 20:23-39.

[10] Clark WW. Hearing: The effect of noise. Otolaryngolo Head Neck Surgery. 1992; 106:669-764.

[11] Coensel B, Muer T, Yperman I, Botteldooren D. The influence of traffic flow dynamics on urban soundscapes. Applied Acoustics. 2005; 66:175-194.

[12] Dannenberg AL, Jackson JR, Frumkin H, et al. The impact of community design and land-use choices on public health. American Journal Public Health. 2003; 93:1500-150.

[13] Dasgupta M, Dasgupta SN. Urbanization in India: Revisiting the Energy Aspect and Policy Issues. 2015.

[14] Dinno A, Powell C, King MM. A study of riders' noise exposure on a bay area rapid transit trains. Journal of Urban Health. 2011; 88:1-13.

[15] Du S, Rompaey AV, Shi P, Wang J. A Dual Effect of Urban Expansion on Flood Risk in the Pearl River Delta (China) Revealed by Land-Use Scenarios and Direct Runoff Simulation. Natural Hazards. 2015; 77:111-128.

[16] Ebare MN, Omuemu VO, Isah EC. Assessment of noise levels generated by music shops in an urban city in Nigeria. Public Health. 2011; 125(9):660-664.

[17] Egunjobi L. Urban environmental noise pollution in Nigeria. Habitat International. 1986; 10(3):235-244.

[18] Ferrara A, Salvati L, Sabbi A, Colantoni A. Soil resources, land cover Changes and rural areas: Towards a spatial mismatch? Science Total Environment. 2014; 478:116-122.

[19] Freiberg A, Schefter C, Girbig M, Murta VC, Seidler A. Health effects of wind turbines on humans in residential settings:Results of a scoping review. Environmental Research. 2019; 169:446-463.

[20] Galea S, Ahern J, Rudenstine S, Wallace Z, Vlahov D. Urban built environment and depression: a multilevel analysis. Journal of Epidemiology of Community Health. 2005; 59:822-827.

[21] Goldsmith M. Discord: The Story of Noise. Oxford University Press; Oxford, UK. 2012; 1-2.

[22] Goines L,Hagler L. Noise Pollution: A Modern Plague. Southern Medical Journal. 2007; 100: $287-294$.

[23] Grossmann I, Varnum MEW. Social Structure, Infectious Diseases, Disasters, Secularism and Cultural Change in America. Psychological Science. 2015; 26:311-324. 
[24] Gumperz JJ. Forward: Socio-cultural dimensions of language change. In: Blount G., Sanches M., editors. Sociocultural Dimensions of Language Change. Academic Press; London, UK. 1977.

[25] Hammer MS, Swinburn TK, Neitzel RL. Environmental noise pollution in the United States: Developing an Effective Public Health Response. Environmental Health Perspective. 2014; 122:115-119.

[26] Hessel PA. Hearing loss among construction workers in Edmonton, Alberta, Canada. Journal of Occupational and Environmental Medicine. 2000; 42(1):57-63.

[27] Hessel PA, Sluis-Cremer GK. Hearing loss in white South African gold miners. South. African. Medical Journal. 1987; 71:364-367.

[28] Hinchcliffe R. Review: Global perspective of noise-induced hearing loss as exemplified by Nigeria. Journal of Audiological Medicine. 2002; 11(1):1-24.

[29] Ibhadode O, Tenebe IT, Emenike PC, Adesina O, Okougha AF, Aitanke FO. Assessment of noise-levels of generatorsets in seven cities of South-Southern Nigeria. African Journal of Science and Technological Innovative Development. 2018; 10(2):125-135.

[30] Jiang L, O'Neill BC. Global urbanization projections for the Shared Socioeconomic Pathways. Global Environmental Change. 2015.

[31] Kaczynski A, Potwarka L, Saelens B. Association of park size, distance, and features with physical activity in neighborhood parks. American Journal of Public Health. 2008;98:1451-1456.

[32] Kaushal SS, McDowell WH, Wollheim WM. Tracking evolution of urban biogeochemical cycles: Past, present, and future. Biogeochemistry. 2014; 121:1-21.

[33] Khilman T. Noise Pollution in Cities. In: Proceedings of the Seminar Environmental Aspects of Urbanization, Gothenburg, Sweden. 2004.

[34] Khresat SL. Degradation Causes and Sustainable Land Management Practices in Southern Jordan. 2015.

[35] Kiernan V. Noise pollution robs kids of languages skills. New Scientist 5.1997.

[36] Lai P. Noise Pollution. In: Theodore K Mary, Theodore Louis., editors. Major Environmental Issues Facing the 21st Century. NJ: Upper Saddle River. 1996; 389-396.

[37] Levak K, Horvat M, Domitrović H. Effects of noise on humans, ELMAR, 50th ed. IEEE; pp. 333-336. International Symposium. 2008.

[38] Liberman MC, Dodds LW. Single-neuron labeling and chronic cochlear pathology. III. Stereocilia damage and alterations of threshold tuning curves. Hear Resources. 1984; 16:55-74.

[39] Lin B, Ouyang X. Energy demand in China: Comparison of characteristics between the US and China in rapid urbanization stage. Journal of Pure Applied Science. 2014; 79:128-139.

[40] Luo J, Siemers BM, Koselj K. How Anthropogenic Noise Affects Foraging. Global Change Biology. 2015.

[41] Maleki K, Hosseini SM,Nasiri P. The Effect of Pure and Mixed Plantations of Robinia pseudoacasia and Pinus eldarica on Traffic Noise Decrease. International Journal of Environmental Science. 2010; 12.

[42] Michaud DS, Keith SE, McMurchy D. Annoyance and disturbance of daily activities from road traffic noise in Canada. Journal of Acoustics Social Americans. 2008; 123(2):784-792.

[43] Miedema HM. Annoyance caused by environmental noise: Elements for evidence-based noise policies. Journal of Social Issues. 2007; 63:41-57.

[44] Min JY, Min KB. Cumulative exposure to nighttime environmental noise and the incidence of peptic ulcer. Environment International. 2018; 121(Pt 2):1172-1178.

[45] Münzel T, Gori T, Babisch W, Basner M. Cardiovascular Effects of Environmental Noise Exposure. European Heart Journal. 2014; 35:829-836.

[46] Nilsson ME. Soundscape quality in urban open spaces. Proc Inter Noise. 2007.

[47] Noise Control Act (NCA). Noise Control Act of 1972. Public Law 92-574. Identification of Major Noise Sources. Noise Criteria and Control Technology. 
[48] Ntui AI. Noise sources and levels at the University of Calabar Library, Calabar, Nigeria. African Journal of Library Archives Information Science. 2009; 19(1):53-63.

[49] Olokesusi F. An assessment of hotels in Abeokuta, Nigeria and its implications for tourists. International Journal of Hospitality Management. 1990; 9(2):125-134.

[50] Oloruntoba EO, Ademola RA, Sridhar MKC, Agbola SA, Omokhodion FO, Ana GREE, Alabi RT. Urban environmental noise pollution and perceived health effects in Ibadan, Nigeria. African J Biomedical Resources. 2012; 15(2):7784.

[51] Oh M, Shin K, Kim K,Shin J. Influence of noise exposure on cardio-cerebrovascular disease in Korea. Science Total Environment. 2005; 651:1867-1876.

[52] Oyedepo OJ, Ekom RI, Ajala KA. Analysis of traffic noise along oyemekun - oba-adesida road Akure, Ondo state Nigeria. Journal of Engineering Science Technology. 2013;6(1):72-77.

[53] Paiva KM, Cardoso MR, Zannin PHT. Exposure to road traffic noise: Annoyance, perception and associated factors among Brazil's adult population. Science Total Environment. 2019; 650:978-986.

[54] Pandya GH. Assessment of traffic noise and its impact on the community. International, Journal of Environmental Studies. 2003; 60:595-602.

[55] Patil NS, Kumar VH, Bhaskara AN. Solid Waste Management and Impact of Landfill Leachate on Groundwater in Hassan City, Karnataka. International Journal of Engineering Resources Technology. 2014; 3:166-169.

[56] Potter RB, Lloyd-Evans S. The Cities in the Developing World. Routledge; Abingdon, UK. 2014; 3-15.

[57] Radun J, Hongisto V, Suokas M. Variables associated with wind turbine noise annoyance and sleep disturbance. Building Environment. 2019; 150:339-348.

[58] Ravindra K, Kaur K, Mor S. System Analysis of Municipal Solid Waste Management in Chandigarh and Minimization Practices for Cleaner Emissions. Journal of Clean Production. 2014; 89:251-256.

[59] Regecová V, Kellerová E. Effects of urban noise pollution on blood pressure and heart rate in preschool children. Journal of Hypertension. 1995; 13:405-412.

[60] Sadorsky P. The effect of urbanization on $\mathrm{CO}_{2}$ emissions in emerging economies. Energy Economics. 2014; 41:147-153.

[61] Sahu S, Nair SJ, Sharma PK. Review on Solid Waste Management Practice in India: A State of Art. International Journal of Innovative Resources Development. 2014; 3:261-264.

[62] Sears CG, Braun JM, Ryan PH, Xu Y, Werner EF, Lanphear BP, Wellenius GA. The association of traffic-related air and noise pollution with maternal blood pressure and hypertensive disorders of pregnancy in the HOME study cohort. Environment International. 2018; 121:574-581.

[63] Seto ETW, Holt A, Rivard T, Bhatia R. Spatial distribution of traffic induced noise exposures in a US city: an analytic tool for assessing the health impacts of urban planning decisions. International Journal of Health Geography. 2007; 6:24.

[64] Shaheen N. The impact of Noise Pollution on patients in general hospital Rawalpindi: a case study. Proceedings of seminar on critical issues in Pakistan's health care, Islamabad. 2013.

[65] Shendell DG, Ana GREE, Brown GE, Sridhar MKC. Assessment of noise and associated health impacts at selected secondary schools in Ibadan, Nigeria. Journal of Environment and Public Health. 2009.

[66] Stansfeld SA, Berglund B, Clark C, et al. Aircraft and road traffic and children's cognition and health: a crossnational study. Lancet. 2005; 365:1942-1949.

[67] Sobotova L, Jurkovicova J, Stefanikova Z, et al. Community response to environmental noise and the impact on cardiovascular risk score. Science Total Environment. 2010; 408:1264-1270.

[68] Talaska AE, Schacht J. Mechanisms of noise damage of the cochlea. Audiological Medicine. 2007; 5:3-9.

[69] Wang L, Lyons L. Fish and Benthic macro invertebrate assemblages as indicators of stream degradation in urbanizing watersheds. In: Simon T.P., editor. Biological Response Signatures: Indicator Patterns Using Aquatic Communities. CRC Press; Florida, FL, USA. 2003; 227-249.

[70] WHO. United Nations Road Safety Collaboration: A Handbook of Partner Profiles. World Health Organization; Geneva, Switzerland. 2005. 
[71] Wiedinmyer C, Yokelson RJ, Gullett BK. Global Emissions of Trace Gases, Particulate Matter, and Hazardous Air Pollutants from Open Burning of Domestic Waste. Environment Science Technology 2014; 48:9523-9530.

[72] Zhao J, Zhu C, Zhao S. Comparing the Spatiotemporal Dynamics of Urbanization in Moderately Developed Chinese Cities over the Past Three Decades: Case of Nanjing and Xi'an. Journal of Urban Planning Development. 2014. 